prescription and use of concomitant drugs in all patients admitted to the hospital with upper gastrointestinal haemorrhage from October-1999 to November-2000. All patient underwent endoscopy to assess the type of gastroscopic lesion and the presence of Helicobacter pylori. Requirements of blood transfusion and surgery were also noted.

Results A total 63 (29\%) out of 216 patients admitted with upper gastrointestinal haemorrhage were using NSAIDs $(60 \%$ aspirin, 16\% piroxicam, 13\% diclofenac, 6\% combined and 5\% other) during a median of 7.5 days (range 1- $>100$ days). Median patients' age was 65 years (range 18-90). NSAIDs were prescribed for pain relieve (75\%), platelet anti-aggregation $(19 \%)$ or both $(6 \%)$. Indication for prescription was done by rheumathology consultants $(0 \%)$, general practitioners $(25 \%)$, other consultants (33\%) and self-prescribed (41\%). Location of lesions at endoscopy were: esophageal (5\%), gastric (35\%), duodenal (43\%) and, multiple lesions (17\%). Helicobacter pylori was present in $28(70 \%)$ out of 40 samples. A total of $44(70 \%)$ patients had at least one risk factor for NSAIDs gastropathy of whom only $2(4 \%)$ were receiving prophylaxis with protein pump inhibitors and $1(2 \%)$ with H2-blockers. NSAIDs gastrointestional haemorrhage accounted for a total of 346 admission days, $40(63 \%)$ patients needed blood transfusion and one $(1 \%)$ suffered surgery.

Conclusion Self-prescription is a common cause of NSAIDs gastrointestinal haemorrhage. Only a minor proportion of patients with risk factors for NSAIDs gastropathy receive appropriate prophylaxis with protein pump inhibitors.

\section{THU0217 JOINT HIPERMOBILITY SINDROME: A PROSPECTIVE STUDY OF ARTICULAR AND NON-RHEUMATIC MANIFESTATION IN A VENEZUELAN POPULATION}

F Riano, O Sanchez, N Pena, Z Tinedo. Rheumatology, Hospital Central Maracay, Maracay, Venezuela

10.1136/annrheumdis-2001.749

\section{Background}

Objectives Although Joint Hypermobility Sindrome (JHS) is a common condition, there are clearly a number of articular and non-articular manifestations. Because of this, one study of subjects with JHS was performed in our country.

Methods A prospective, descriptive and analytical of 41 patients attending our Unit from February up to September 1999, and who fulfilled the Beighton Scale for JHS (Beighton P, Grahame R, Bird H (1999) Assessment of hipermobility. In Beighton P (ed) Hypermobility of Joints. Spring, London, pp:9-22) was made. The mean age was 32 years, there were 35 females $(85.4 \%)$ and 6 males (14.6\%). All over the group were evaluated through Beighton Scale (BS), being 4 points the lowest and 9 points the highest. All subjects were examined for echocardiogram and a gynaecological exam was performed in all sexually active women.

Results 11 patients $(26.8 \%)$ had 9 points in the BS and 1 patient $(2.4 \%)$, being the mean of the group of 6 points. The dorsiflexion of fifth finger was found in all subjects. When comparing passive apposition of the thumb of the flexor aspect of the forearm, with the highest point, there was a good correlation $(\mathrm{p}=$ $0.003)$. Patients under 30 years had higher points in the BS $(\mathrm{p}=$ 0.005). Arthralgia was present in 29 subjects (70.78\%), mainly in women $(\mathrm{p}=0.001)$. Flat feet was found in 23 patients $(56.09 \%)$ and Marfanoid habitus in 23 patients. Mitral valve prolapse (MVP) was found in 24 patients $(58.53 \%)$, the great majority under 30 years and with higher points in the BS. Uterine prolapse was diagnosed in 12 women of the 24 examined $(50.0 \%)$, most of them over 30 years, no significance correlation was showed between uterine prolapse and points in the BS.

Conclusion In our study arthralgias particularly of the knees was found, and among extrarticular MVP was the commonest one. We also found a higher incidence of uterine prolapse than expected for women in this age.

\section{THU0218 SUCCESSFUL TREATMENT OF WEBER CHRISTIAN DISEASE (WCD) WITH THALIDOMIDE IN A PATIENT FAILING MULTIPLE OTHER MEDICAL THERAPIES}

HR Barthel. Koenigstein, Germany

10.1136/annrheumdis-2001.750

\section{Background}

Objectives A case of idiopathic nodular panniculitis (WCD) with recurrent febrile episodes resistant to corticosteroids and methotrexate (MTX) in alternating combin. with hydroxychloroquine (HCQ), azathioprine, cyclosporine, colchicine, and doxycycline is described. Thalidomide $50-100 \mathrm{mg} / \mathrm{d}$ induced a remission now since $2 \mathrm{y}$.

Methods CASE REPORT:The patient is a 65y.o. German male who presented first in 3/1998 with a $2-y$. hist. of recur. febr. attacks with 1-2 cm, painful, palp., subc., non-draining, eryth. nodules occurr. on lower legs, backside of upper thighs, lower back, and upper arms. 3 consec. biop. showed lobular and septal panniculitis. Lab. exam. revealed mild leukopenia $(2500 / \mathrm{mm} 3)$, mild thrombocytopenia, CRP $2.5 \mathrm{mg} / \mathrm{dl}$, sed.-rate $50 \mathrm{~mm} / \mathrm{h}$, ferritin $900 \mathrm{ng} / \mathrm{ml}$. Blood cultures, ANA, ANCA, RF, C3, C4, C1qInhib., cardiolip.-AB, immunoelpho., borr. burgd. ser., a1-antitryp., serum amyl. and lip., and UA were all normal or neg. Bone marrow biopsy showed unspecific changes. Chest $\mathrm{x}$-ray was normal. Abdominal CT gave no hint for lymphoma or malignancy. Despite $25 \mathrm{mg} / \mathrm{d}$ of prednisolone and $20 \mathrm{mg}$ weekly MTX recurrent attacks occurred. Various drugs were tried in combination with MTX in order to lower steroids such as azathioprine $100 \mathrm{mg} / \mathrm{d}$, HCQ $400 \mathrm{mg} / \mathrm{d}$, doxycyc. $200 \mathrm{mg} / \mathrm{d}$, colchicine $1.2 \mathrm{mg} / \mathrm{d}$, and cyclosporine $(200 \mathrm{mg} / \mathrm{d})$, all without improvement.

In 3/1999 sympt. worsened and CRP rose intermitt. to 16 $\mathrm{mg} / \mathrm{dl}$, further lab. exam. showed persistence of leukopenia $3400 / \mathrm{mm} 3$, normal platelet counts, but drop of haemoglobin to 9.5 without clinical evidence of a GI-bleed. A new bone marrow biopsy revealed lymphocytic hyperplasia with no histol. or cytol. support for erythrophagocytosis.

Thalidomide initially $150 \mathrm{mg} / \mathrm{d}$ at night, then after 2 weeks at $100 \mathrm{mg} / \mathrm{d}$ was started and induced disappearance of febrile attacks and subcutaneous nodules. CPR, sedimentation-rate, and haematological findings normalised. Glucocorticosteroids and MTX were discontinued. After 3 months thalidomide was reduced to $50 \mathrm{mg} / \mathrm{d}$ with infrequent mild relapses (with mild subcutaneous nodules only), which disappear within 1-2 day with temporary thalidomide dose increase to $100 \mathrm{mg} / \mathrm{d}$.

Results

Conclusion Rarity of WCD has so far hampered a controlled therapeutic trial with any drug. Only case reports with various drugs exist suggesting mostly corticosteroids, MTX, HCQ, cyclosporine, which all failed in this case. The use of thalidomide in WCD is suggested by clinical similarities to erythema 
nodosum leprosum and lupus profundus panniculitis, immunologic mediated conditions responding well to thalidomide. There has been so far only one other report of thalidomide use in WCD. 24 years ago a favourable response in a 23 y.o. Female from Malaysia was reported. This patient had a remission, which was ongoing despite stopping of all medications after treatment with thalidomide of only 13 weeks. The question of a possible spontaneous remission asked by the describing authors remains unanswered. To the contrary, in the here described case repeated reduction of thalidomide below $100 \mathrm{mg} / \mathrm{dl}$ caused mild recurrence of sympt., responding immediately to dose increase to 100 mg.

Thalidomide?s anti-TNFa modulatory and anti-angiogenic effects have recently been rediscovered also for treatment of other autoimmune diseases. Superior tolerability and side-effect profile (compared to corticosteroids and immunosuppressives) make thalidomide a first line treatment consideration for chronic WCD in patients without childbearing potential.

\section{THU0219 RETROSPECTIVE EVALUATION OF 180 PATIENTS WHO WERE DIAGNOSED AS UNDIFFERENTIATED CONNECTIVE TISSUE DISEASE}

E Doganavsargil, F Oksel, G Keser, V Inal, K Aksu. Rheumatology, Ege University Hospital, Izmir, Turkey

\subsection{6/annrheumdis-2001.751}

\section{Background}

Objectives To review the outcome and diagnosis of patients whose initial clinical and laboratory findings were suggestive of a well established and undifferentiated connective tissue disease (uCTD), without fulfilling the diagnostic criteria of any connective tissue disease.

Methods Medical records of patients being followed up by Ege University rheumatology department between 1990 and 1999 were retrospectively screened. The data of 478 patients, constituting $18 \%$ of the total, whose initial diagnosis was uCTD, were further investigated. Patients with missing data were omitted and only 180 patients having reliable and complete initial clinical and laboratory data with regular controls were included.

Results The mean ages of 180 patients (F/M:173/7) at the time of initial clinical symptoms and at the time of diagnosis of uCTD were $35 \pm 12$ years and $38 \pm 12$ years, respectively. The distribution of initial symptoms and clinical findings were as follows: arthralgia/arthritis 97.2\%, Raynaud phenomenon (RP) $30.5 \%$, mucocutaneous findings $68.2 \%$, symptoms of keratoconjunktivitis sicca $14.4 \%$. It was notable that none of the patients had presented with initial symptoms or clinical finding reflecting direct involvement of a specific organ.

In the final evaluation, 46 out of 180 patients (25.5\%) were found to evolve into a definite clinical diagnosis: Sjögren's syndrome 21 (11.6\%), systemic lupus erythematosus $8(4.4 \%)$, rheumatoid arthritis 8 (4.4\%), CREST syndrome 7 (3.8\%), diffuse systemic sclerosis 1 and seronagative polyarthritis 1 . In 5 patients a nonrheumatologic diagnosis was made, while in 11 patients fibromyalgia was diagnosed. The diagnosis of 118 $(65 \%)$ patients (F/M:115/3) remained unchanged.

The evaluation of initial clinical and laboratory parameters with respect to their contribution to final diagnosis revealed that, presence of Raynaud phenomenon and anti-centromeric antibodies were highly suggestive of later diagnosis of limited ScS. On the other hand, anti-dsDNA antibodies, leucopenia and thrombocytopenia, which are important parameters in well established SLE, were initially unpredictive of later SLE development in patients whose initial diagnosis was uCTD.

Conclusion In most of the patients whose initial diagnosis was $\mathrm{uCTD}$, the disease tends to remain undifferentiated.

\section{THU0220 AN ESTIMATION OF THE PREVALENCE OF HYPERMOBILITY}

${ }^{1} \mathrm{M}$ Gumà, ${ }^{2} \mathrm{~J}$ Roca, ${ }^{1} \mathrm{~S}$ Holgado, 'M Valls-Roc, ${ }^{1} \mathrm{E}$ Casado, ${ }^{3} \mathrm{~J}$ Forcada, ${ }^{1} \mathrm{JC}$ Duro, ${ }^{1} \mathrm{~A}$ Olive, ${ }^{1} \mathrm{X}$ Tena. ${ }^{1}$ Rheumatology; ${ }^{2}$ Epidemiology; ${ }^{3} G$ P, Hospital Universitari Germans Trias I Pujol, Badalona, Spain

\subsection{6/annrheumdis-2001.752}

Background Hypermobility is associated with several rheumatic manifestations. The association with SLE is controversial.

Objectives To determine the prevalence of hypermobility in two different populations: a general practitioner (GP) office and outpatients clinic of a referral rheumatology hospital.

Methods 280 patients (193 females, 87 males); mean age 44.7 \pm 11.2 were consecutively reviewed in a GP office. 370 patients (233 females, 84 males); mean age $50.5 \pm 16.8$ were consecutively visited at the out-patients rheumatology clinic. Hypermobility was evaluated following the criteria of Carter-Beighton (hypermobility $>4$ points).

Results Hypermobility was present in $42 / 280$ (15\%) at the GP office and in $81 / 317(25 \%)$ in the out patients rheumatology clinic.

\begin{tabular}{lllll}
\multicolumn{5}{l}{ Abstract THU0220 Table 1} \\
\hline General practitioner & \multicolumn{3}{l}{ Hospital } \\
\hline Hypermobility & YES & NO & YES & NO \\
Age & $28 \pm 11.7$ & $47 \pm 18.3$ & $38.9 \pm 14.2$ & $54 \pm 15.9$ \\
Sex (F/M) & $5.8 / 1$ & $1 / 1.2$ & $3,7 / 1$ & $1 / 1.3$ \\
Criteria & $5.1 \pm 1$ & $0.6 \pm 1$ & $5.6 \pm 1.6$ & $0.5 \pm 0.9$ \\
\hline
\end{tabular}

Conclusion The prevalence of hypermobility at the GP office and a rheumatology clinic is high. Furthermore it is close to the prevalence of hypermobility in the general population.

\section{THU0221 OSTEONECROSIS AND HIV INFECTION: REPORT OF ELEVEN CASES}

${ }^{1} \mathrm{M}$ Valls-Roc, ${ }^{1} \mathrm{~V}$ Ortiz-Santamaria, ${ }^{1} \mathrm{~A}$ Olive, ${ }^{2} \mathrm{M}$ Cervantes, ${ }^{2} \mathrm{G}$ Gratacos, ${ }^{3} \mathrm{G}$ Sirera, ${ }^{3} \mathrm{C}$ Tural, ${ }^{3}$ E Negredo, ${ }^{1} \mathrm{X}$ Tena, ${ }^{3} \mathrm{~B}$ Clotet. ${ }^{1}$ Rheumatology Service, Hospital Universitari Germans Trias I Pujol, Badalona, Spain; ${ }^{2}$ Rheumatology Service, Consorci Sanitari Parc Tauli, Sabadell, Spain; ${ }^{3}$ HIV Unit, Hospital Universitari Germans Trias I Pujol, Badalona, Spain

\subsection{6/annrheumdis-2001.753}

Background A vascular necrosi (AVN) has been described in the setting of HIV infection. No epidemiological studies to determine the higher incidence of AVN in HIV+ patients are available. Protease inhibitor containing regimens (PI-CR) have been considered an additional risk factor for developing AVN.

Objectives To report the clinical findings of $11 \mathrm{HIV}+$ patients with AVN.

Methods Retrospective review of clinical and radiological charts of 11 patients diagnosed of AVN. 